\title{
Postsurgical Compliance and Eating Behavior 5 Years After Surgery
}

Citation for published version (APA):

Konings, G., Drukker, M., Mulkens, S., Severeijns, R., van Os, J., \& Ponds, R. (2020). Postsurgical Compliance and Eating Behavior 5 Years After Surgery. Bariatric Surgical Practice and Patient Care, 15(3), 148-154. https://doi.org/10.1089/bari.2019.0049

Document status and date:

Published: 01/09/2020

DOI:

10.1089/bari.2019.0049

Document Version:

Publisher's PDF, also known as Version of record

Document license:

Taverne

Please check the document version of this publication:

- A submitted manuscript is the version of the article upon submission and before peer-review. There can be important differences between the submitted version and the official published version of record.

People interested in the research are advised to contact the author for the final version of the publication, or visit the DOI to the publisher's website.

- The final author version and the galley proof are versions of the publication after peer review.

- The final published version features the final layout of the paper including the volume, issue and page numbers.

Link to publication

\footnotetext{
General rights rights.

- You may freely distribute the URL identifying the publication in the public portal. please follow below link for the End User Agreement:

www.umlib.nl/taverne-license

Take down policy

If you believe that this document breaches copyright please contact us at:

repository@maastrichtuniversity.nl

providing details and we will investigate your claim.
}

Copyright and moral rights for the publications made accessible in the public portal are retained by the authors and/or other copyright owners and it is a condition of accessing publications that users recognise and abide by the legal requirements associated with these

- Users may download and print one copy of any publication from the public portal for the purpose of private study or research.

- You may not further distribute the material or use it for any profit-making activity or commercial gain

If the publication is distributed under the terms of Article $25 \mathrm{fa}$ of the Dutch Copyright Act, indicated by the "Taverne" license above, 


\title{
Postsurgical Compliance and Eating Behavior 5 Years After Surgery
}

\author{
Gerdy Konings, BA, ${ }^{1,2}$ Marjan Drukker, PhD, ${ }^{1}$ Sandra Mulkens, PhD, ${ }^{1,3}$ Ruud Severeijns, PhD, ${ }^{1,2}$ \\ Jim van Os, MD, $\mathrm{PhD}^{1,4}$ and Rudolf Ponds, $\mathrm{PhD}^{1,2}$
}

Background: Bariatric surgery requires long-term changes in eating behavior. Bariatric patients can experience difficulties adhering to postsurgical dietary guidelines. Long-term data are scarce.

Methods: Individuals $(N=101)$ who had undergone bariatric surgery (mean 4.6 years ago) completed a survey collecting data on weight, changes in eating patterns, compensatory behavior, and compliance with postsurgical dietary guidelines. The associations between healthy and unhealthy behaviors, weight loss, and patient satisfaction were analyzed.

Results: A substantial number of patients mentioned nonadherence to the guidelines. In particular, postoperative restrained eating, nonvitamin use, and excessive exercise more than three times per week. These behaviors were associated with less weight loss, but only the association with postoperative restrained eating was statistically significant. In addition, reporting of unhealthy behaviors was associated with less satisfaction with respect to the bariatric surgery trajectory.

Conclusion: Adherence to postoperative behavioral guidelines remains essential at follow-up $\sim 5$ years after bariatric surgery and should remain a focus of clinical follow-up to prevent negative impacts on weight, health, and satisfaction with the trajectory after bariatric surgery. The present results need to be replicated, and more research is necessary to unravel the effect of unhealthy behaviors on long-term outcomes following bariatric surgery.

Keywords: long-term outcome, bariatric surgery, (non-)adherence, eating behaviour, patient perspective

\section{Introduction}

B ARIATRIC SURGERY PROVIDES substantial effects on weight loss. However, a subgroup of patients fails to comply with the prescribed lifetime changes in eating behavior $^{1}$ and returns to maladaptive eating within 5 years, posing a challenge for maintaining weight loss. ${ }^{2}$ Short-term studies reported a positive effect on aspects of eating behavior, such as decreased levels of hunger, disinhibition, restrictive eating, and binge eating, but these improvements declined after the initial surgical effect waned. ${ }^{3}$

Long-term studies conducted to date found significant patient-to-patient variability. ${ }^{4}$ Various factors played a role in suboptimal weight loss, such as eating behavior, diet management, psychological condition, ${ }^{1}$ medical factors, and physical activity. ${ }^{5} \mathrm{~A}$ range of physical as well as be- havioral variables are thought to predict the extent of postoperative weight loss. ${ }^{2}$ Success has been associated with many variables such as having a greater initial weight loss, striving for a self-determined target weight, engaging in a physically active lifestyle, having a regular meal pattern, including breakfast, having healthier eating habits, controlling overeating, and self-monitoring behaviors. ${ }^{1,6}$ Weight regain was common and varied between $28 \%$ and $50 \% .{ }^{1}$ Weight regain has been associated with a history of weight cycling, disinhibited eating, binge eating, increased hunger, eating in response to negative emotions, and more passive reactions to problems. ${ }^{6}$ Suboptimal results have been attributed to poor compliance, resulting in maladaptive eating behavior. ${ }^{2,7}$ Compliance also plays an important role in achieving a satisfactory level of well-being and quality of life. ${ }^{8}$

\footnotetext{
${ }^{1}$ Department of Psychiatry and Psychology, School of Mental Health and Neuroscience (MHeNS), Maastricht University, Maastricht, The Netherlands.

${ }^{2}$ Department of Medical Psychology, Maastricht University Medical Centre (MUMC), Maastricht, The Netherlands.

${ }^{3}$ Department of Clinical Psychological Science, Section on Eating Disorders and Obesity, Maastricht University, Maastricht, The Netherlands.

${ }^{4}$ Department of Psychosis Studies, King's College London, King's Health Partners, Institute of Psychiatry, London, United Kingdom.
} 
Implementation of lifestyle changes seems to be a key requirement for success. ${ }^{9}$ Dietary guidelines are provided depending on the type of surgical procedure (restrictive or malabsorption). Examples are increased meal frequency with smaller amounts per meal, no liquids during meals, no carbonated beverages or alcohol consumption, and lifetime vitamin supplementation. ${ }^{10}$ Dietary guidance is part of the long-term management to maximize weight loss. ${ }^{10}$ Longterm studies assessing mental health and eating behavior after surgery are scarce, even though they are considered essential in determining weight loss in the long term. ${ }^{7}$ The understanding of long-term postoperative eating behavior is still limited and a 2 -year follow-up is not sufficient. ${ }^{9}$ Studies assessing postoperative dietary and behavioral changes more than 2 years after surgery are urgently needed. ${ }^{3}$

The present survey adds to the small pool of long-term results focusing on eating behavior and compliance with surgical dietary guidelines. The first aim was to assess postoperative changes in eating behavior as well as compliance with dietary guidelines and the effect of healthy behavior on weight loss. The second aim was to assess the associations between compliance with dietary guidelines and satisfaction regarding their weight loss trajectory.

\section{Methods}

Approval for the study was granted by the Medical Ethics Committee of the Maastricht University Medical Centre (MUMC). The study was conducted in accordance with the provisions in the current version of the Declaration of Helsinki.

\section{Participants}

All patients opting for bariatric surgery were referred by the department of surgery at the MUMC for psychological screening. In 2005, a list including 490 names referred for screening between 1996 and 2002 was available. In total, 200 names were checked. Most names were from the 2000 and 2001 list. Individuals on this list were tracked down by phone and were invited to participate until a predefined number of 150 subjects agreed to participate. The inclusion criterion was having bariatric surgery performed at least 2 years before the inclusion date (hereafter after surgery). Among those on the list, some persons could not be tracked down $(n=45)$, did not agree to participate $(n=4)$, had no bariatric surgery after screening $(n=7)$, or died $(n=1)$. Therefore, 49 participants were eligible, but did not participate in the study (nonresponders).

As the names were selected consecutively and stratified by year, this selection procedure was expected to result in a representative subgroup.

\section{Procedure}

In 2005, all participants received an envelope by ordinary mail and a postage-paid envelope to facilitate a return response. The envelope included an informed consent form as well as a written survey. After informed consent was obtained, demographic information and medical information such as preoperative weight, body-mass index (BMI), and postoperative weight at 24 months was obtained from the medical files.

\section{Survey}

Topics of the survey assessed changes in eating behavior, compliance with postsurgical dietary guidelines, compensatory behavior, and alcohol use (Table 1). Formal definitions (e.g., of binge eating) were presented to clarify particular questions. Most questions were answered on a 4-point Likert scale (never, sometimes, often, or always). Within the compensatory behavior section, the answer options were yes and no with an option to add information in an open-ended text field. For questions regarding alcohol, the answer options were yes and no. If alcohol was perceived as a problem, one could indicate if this problem had improved (no, a little, a lot, or resolved) after surgery. No incentives were provided for completion of the survey.

\section{Postoperative healthy and unhealthy behavior}

To study the effect of healthy behavior on weight loss, all items on eating behavior, compensatory behavior, and postsurgical dietary guidelines were dichotomized (often/ always vs. never/sometimes (Table 2). Restrained eating was defined as a conscious effort to skip food or meals to limit and control dietary intake to prevent weight gain or to promote weight loss. Subsequently, a healthy behavior sum score was generated based on the literature. Finally, the healthy behavior sum score was recoded (zero or one

Table 1. Selected 2005 Survey Questions

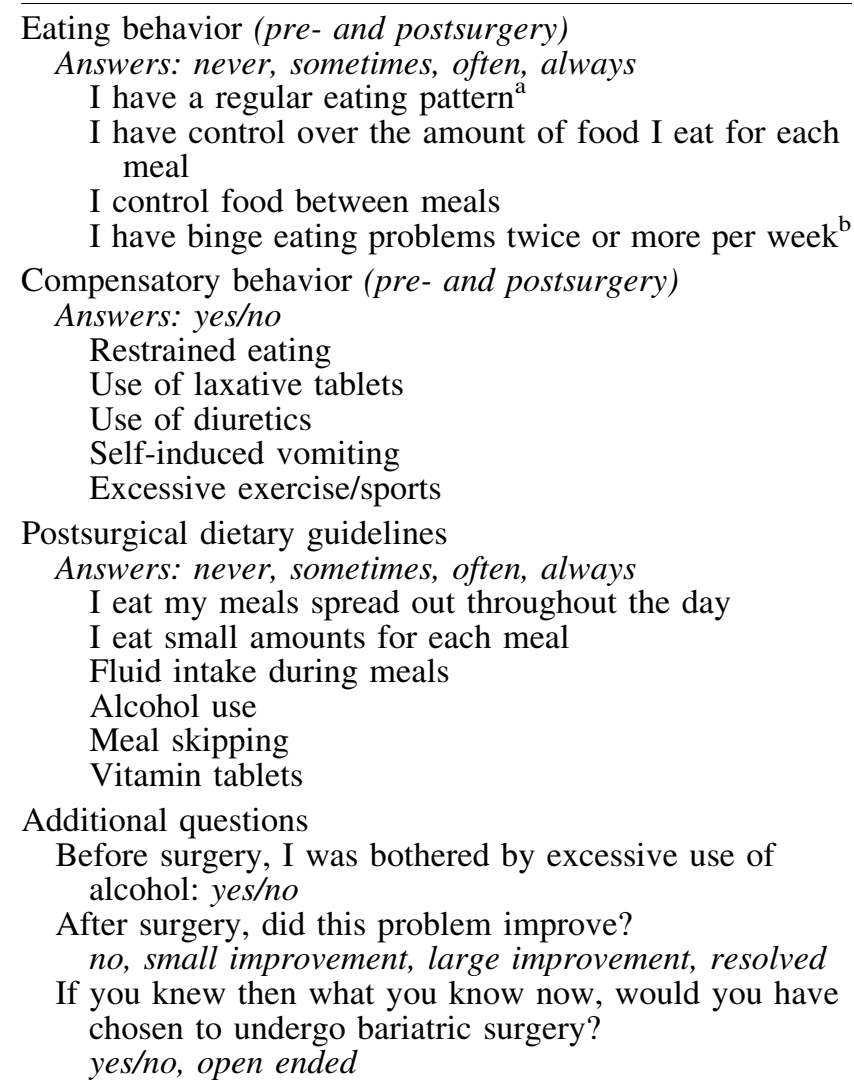

${ }^{\mathrm{a}}$ Three meals per day.

${ }^{\mathrm{b}}$ Eating a large amount of food within a short period (often within $2 \mathrm{~h}$ ). 
Table 2. Changes in Eating Behavior and Postoperative Dietary Compliance

\begin{tabular}{|c|c|c|c|c|c|}
\hline \multirow{2}{*}{$\mathrm{N}=101$} & \multicolumn{2}{|c|}{ Before surgery } & \multicolumn{2}{|c|}{ After surgery } & \multirow[t]{2}{*}{$H / U^{\mathrm{c}}$} \\
\hline & Yes & & Yes & & \\
\hline Restrained eating & 91 & & 26 & & $\mathrm{U}$ \\
\hline \multicolumn{6}{|l|}{ Compensatory behavior (\%) } \\
\hline Laxatives $^{\mathrm{a}}$ & 4 & & 1 & & $\mathrm{U}$ \\
\hline Diuretics $^{\mathrm{a}}$ & 7 & & 0 & & $\mathrm{U}$ \\
\hline Vomiting $^{\mathrm{a}}$ & 2 & & 3 & & $\mathrm{U}$ \\
\hline Exercise/sports ${ }^{\mathrm{b}}$ & 16 & & 24 & & $\mathrm{U}$ \\
\hline Eating behavior (\%) & Always & Never & Always & Never & \\
\hline Regular meals & 18 & 31 & 47 & 10 & $\mathrm{H}$ \\
\hline Control amount of food & 12 & 30 & 56 & 4 & $\mathrm{H}$ \\
\hline Control between meals & 9 & 30 & 42 & 5 & $\mathrm{H}$ \\
\hline Binge eating ${ }^{\mathrm{c}}$ & 15 & 35 & 2 & 73 & $\mathrm{U}$ \\
\hline Dietary guidelines (\%) & & & Always & Never & \\
\hline Meals spread throughout day & & & 29 & 16 & $\mathrm{H}$ \\
\hline Small meals each time & & & 53 & 5 & $\mathrm{H}$ \\
\hline Fluids during meals & & & 12 & 47 & $\mathrm{U}$ \\
\hline Alcohol use & & & 0 & 34 & $\mathrm{U}$ \\
\hline Meal skipping & & & 0 & 28 & $\mathrm{U}$ \\
\hline Vitamin tablets & & & 38 & 22 & $\mathrm{H}$ \\
\hline
\end{tabular}

${ }^{\mathrm{a}}$ Twice per week for at least 3 months.

${ }^{\mathrm{b}}$ At least twice per week for at least 3 months.

${ }^{\mathrm{c}} \mathrm{A}$ large amount of food eaten in a short period of time, at least twice per week.

${ }^{\mathrm{d}}$ Clustered/marked as $\mathrm{H}$ or $\mathrm{U}$ behavior.

$\mathrm{H}$, healthy; U, unhealthy.

unhealthy behavior =healthiest group; two or three unhealthy behaviors = mixed behavior group; and four or more unhealthy behaviors $=$ unhealthiest group).

\section{Patient satisfaction}

Patient's overall satisfaction with respect to the weight loss trajectory following bariatric surgery was assessed using the question: "If you knew then what you know now, would you have chosen to undergo bariatric surgery?" The answer, yes or no, could be substantiated in an open-ended question.

\section{Statistical analyses}

Analyses were performed using STATA, version 13.1, with statistical significance set at $p<0.05$. Chi-square tests and $t$-tests were used to compare responders with nonresponders. To analyze the first aim, differences in preoperative and postoperative eating behaviors and compensatory behavior were analyzed using $t$-tests for continuous variables and chi-square analysis for dichotomous variables. The association between weight loss and eating behavior and compensatory behavior was analyzed using linear regression analysis because the dependent variable was continuous.

To assess the second aim, partial correlations of all variables in Table 1 were calculated and presented in a network using the statistical program $\mathrm{R}$ and the $\mathrm{R}$ package qgraph. ${ }^{11}$

In addition, logistic regression analysis was performed to analyze associations between the healthy behavior total score in three categories and patient satisfaction.

\section{Results}

\section{Demographic data}

In 2005, 101 participants (82 women, 82\%) responded (67\%). The mean age was 44.5 (standard deviation [SD]: 9.6) years. On average, participants' first bariatric surgery occurred 4.6 years before responding to the questionnaire (SD: 2.4; range 1.5-9.7 years). Half of the participants had a primary educational level, $37 \%$ had a secondary educational level, and $13 \%$ had a high educational level. The average initial weight and BMI were $134.5 \mathrm{~kg}$ (SD: 24.1) and $46.5 \mathrm{~kg} / \mathrm{m}^{2}$ (SD: 6.7; range 33.9-69.4), respectively. Laparoscopic adjustable gastric banding (55\%) was used most frequently, followed by vertical banded gastroplasty (39\%) and Roux-en-Y gastric bypass $(6 \%)$. The reoperation rate was $14 \%$.

Nonresponders $(n=49)$ and responders did not differ in gender $(86 \%$ and $82 \%$ women, respectively; chisquare $=0.53$, df $=1, p=0.5)$, preoperative mean age $(36.9$ and 38.3 years, respectively; $t=0.8$; $\mathrm{df}=130, p=0.44$ ), preoperative weight (129.4 and $134.5 \mathrm{~kg}$, respectively; $t=1.1$, $\mathrm{df}=133, p=0.27)$, and initial BMI $\left(45.8\right.$ and $46.5 \mathrm{~kg} / \mathrm{m}^{2}$, respectively; $t=0.5 ; \mathrm{df}=133, p=0.62)$.

\section{Eating behavior}

Table 2 shows the results of the survey regarding pre- and postsurgical eating behavior, compensatory behavior, and dietary compliance.

Significantly more regular eating $(p<0.001)$, control over the amount of food for each meal $(p<0.001)$, and less snacking between meals $(p<0.001)$ after surgery were reported. One in four participants reported binge eating at least sometimes.

\section{Compensatory behavior}

After surgery, restrained eating diminished significantly from $91 \%$ to $26 \%$. Before surgery, laxative or diuretic use was low, but it diminished even further after surgery (n.s.). 
Self-induced vomiting remained the same. Excessive exercise increased from $16 \%$ to $24 \%$. The average weight loss was $7 \mathrm{~kg}$ lower in participants performing excessive exercise, but this result was not statistically significant $(32.8 \mathrm{~kg}$, SD: 20.7 vs. $39.8 \mathrm{~kg}$, SD: $19.1 ; t=-1.54 ; \mathrm{df}=98, p=0.12$ ).

\section{Postsurgical dietary compliance}

After surgery, most of the participants spread meals over the day, ate small meals, and did not consume liquids during meals (Table 2). However, skipping meals was common (Table 1). Approximately one-third of the participants did not use alcohol; $12 \%$ reported frequent use of alcohol. After surgery, $1 \%$ still reported excessive alcohol use, while this was $3 \%$ before surgery.

Approximately $60 \%$ used vitamins often or always. Frequent vitamin users showed, on average, $10 \mathrm{~kg}$ more weight loss than nonfrequent vitamin users $(t=1.6, \mathrm{df}=97, p=0.11)$.

Subjects postoperatively applying restrained eating showed significantly less weight loss than subjects complying with the guideline not to restrain eating, that is, $30.6 \mathrm{~kg}$ (range -10 to $66 \mathrm{~kg}$ ) and $40.7 \mathrm{~kg}$ (range -3 to $92 \mathrm{~kg}$ ), respectively $(t=-2.32, \mathrm{df}=98, p=0.02)$. Weight loss was identical regardless of alcohol use $(t=0.3, \mathrm{df}=97, p=0.73)$ or liquid consumption during meals $(t=-0.18, \mathrm{df}=97$, $p=0.86$ ).

\section{Postoperative healthy behavior and weight loss}

Healthy behavior did not result in significantly more weight loss, although the results pointed in that direction $(p=0.09)$. Comparing subjects with zero or one unhealthy factor with subjects with more than four unhealthy factors also showed no difference in mean weight loss, but again, the results were suggestive ( $42.1 \mathrm{~kg}$ [SD: 19.3$]$ vs. $32.8 \mathrm{~kg}$ [SD: 20.3]; $t=1.85, \mathrm{df}=62, p=0.068)$. Partial correlations of all behaviors in Table 1 were calculated and presented in a network analysis to gain further insight (Fig. 1). The position and size of a circle reflect the amount of influence. Vitamin use had a central position.

\section{Satisfaction regarding the weight loss trajectory}

Participants with more than four unhealthy behavior factors were less satisfied with the trajectory after bariatric surgery than participants with zero or one unhealthy factor (odds ratio $=0.17, p=0.04$ ).

\section{Discussion}

Most behavioral changes after surgery were in compliance with postsurgical guidelines. However, unhealthy behaviors were also found, including postoperative restrained eating, excessive exercise to reduce weight, and low vitamin use. Postoperative restrained eating was associated with less weight loss. All behaviors will be discussed below.

\section{Eating behavior}

About half of the participants complied with eating regular meals, yet skipping meals was common. Weight loss was similar regardless of compliance with this guideline, although significantly less weight loss was found in subjects who still engaged in postoperative restrained eating.
Few studies have focused on postoperative eating patterns. Regular meals were found to contribute positively to longterm weight loss, ${ }^{6}$ but compliance with regular meals decreased over time: $93 \%$ still ate regularly 1 year after surgery and $85 \%$ after the second year. ${ }^{12}$ In accordance with our results, one study mentioned that meal frequency was similar in the group with suboptimal weight loss and in the group with successful weight loss. ${ }^{13}$

Restrained eating is often associated with overeating and is a risk factor for eating disorders. ${ }^{6}$ Studies that focused on postoperative restrained eating are scarce. In a 2-year followup study, $81 \%$ of the patients still tried to lose weight by decreasing caloric and fat intake; the patients avoided not only the products they were advised to but also nutrient-dense foods high in vitamins and minerals, which could result in micronutrient deficiencies. ${ }^{14}$ Restrained eating behavior may also be triggered when expectations regarding postoperative results of weight loss remain unfulfilled. Previous research reported that unrealistic expectations about weight loss were common and that failure to reach a self-determined weight discouraged the persons in their perceived ability to control weight, resulting in the abandonment of advised weight maintenance behaviors. ${ }^{6}$ Thus, although restrained eating was majorly reduced after surgery, the specific meaning of postoperative restrained eating within a substantial part of the participants remained unclear.

\section{Alcohol}

The advice is to stop using high-calorie liquids and alcohol to support weight loss. ${ }^{5}$ Our study found that more than half of the participants still used alcohol, some excessively. It appears that additional interventions are needed to decrease alcohol use after bariatric surgery. Alcohol and high-calorie liquids have been associated with weight gain. ${ }^{6}$ Participants consuming high-calorie liquids lost $<50 \%$ of their excess weight. Additionally, over time, alcohol use increased, particularly in men, and a risk of alcohol dependency has been observed. ${ }^{5}$ In particular, gastric bypass surgery has been associated with increased postoperative alcohol consumption. In line with the theory of symptom substitution, alcohol could replace eating, while the underlying pathology toward eating habits remains inadequately addressed. ${ }^{15}$ Although the present results did not show an association between alcohol use and weight loss, alcohol use should be a topic in longterm follow-up because of the high proportion of subjects who reported violation of the guideline.

\section{Vitamin use}

Vitamin supplementation varied. Most participants used vitamins on a regular basis, but one in five never used vitamins and one in five used vitamins sometimes. Although not significant, compliers lost $10 \mathrm{~kg}$ more weight than subjects using vitamins sometimes or never. Noncompliance could easily contribute to malnutrition and deficiencies. ${ }^{4}$ The failure to use vitamin supplements may result in food urges or cravings, which were found to strongly predict weight regain after surgery. Micronutrient deficiencies are important for not only overall health but also long-term weight maintenance through their role in regulating appetite, hunger, nutrient absorption, metabolic rate, and glucose homeostasis, among other things. ${ }^{4}$ Therefore, less weight loss or weight regain is 


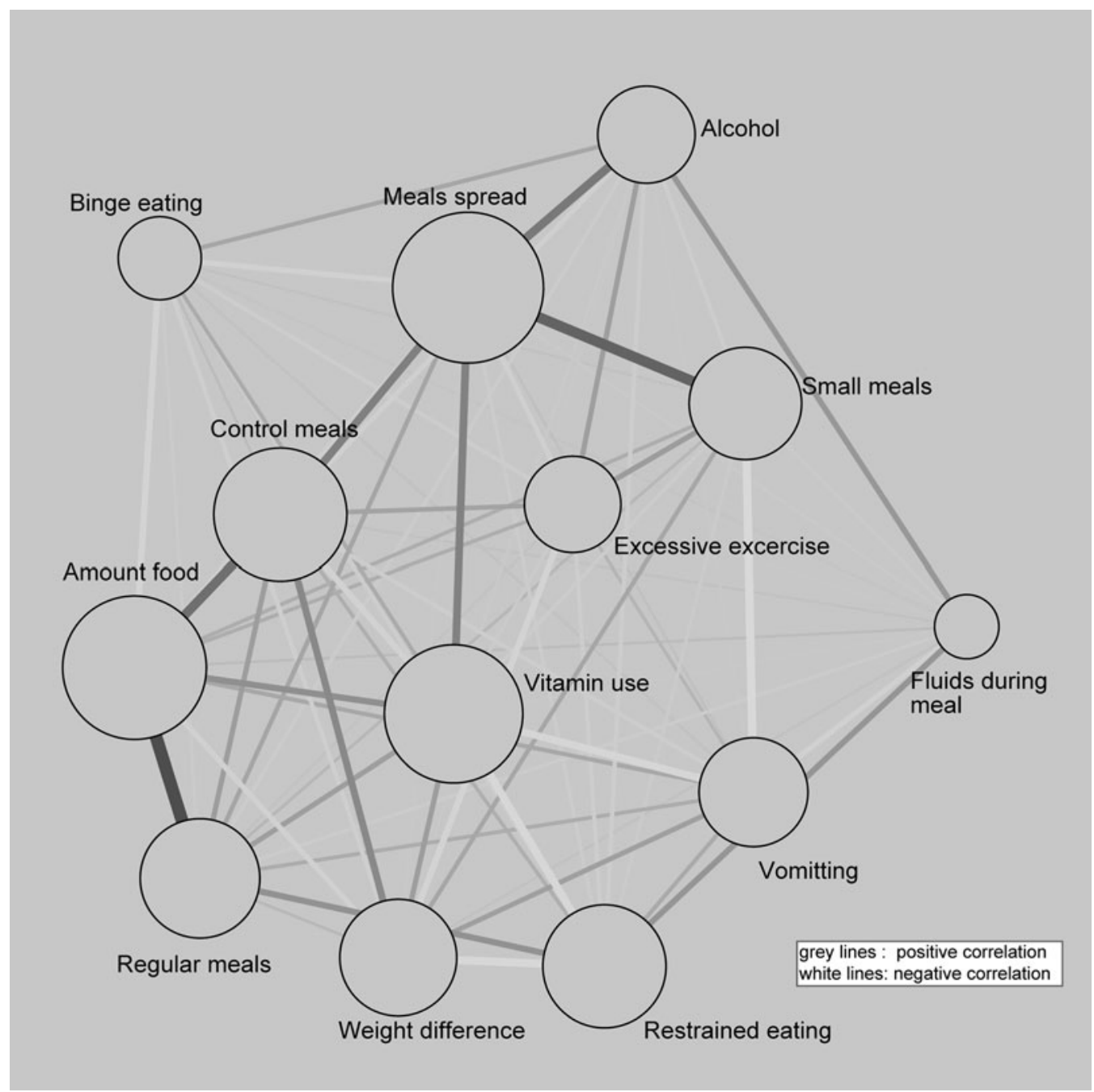

FIG. 1. Partial correlations of all behaviors. Gray lines show positive correlations, and white lines show negative correlations. The position and size of a circle reflect the amount of influence.

plausible for those who do not comply with the vitamin guidelines. The network analysis did place vitamin use as a central factor, but this analysis cannot reveal underlying processes (Fig. 1). Tests to evaluate metabolic and nutritional status are necessary in the long run. ${ }^{5}$

\section{Compensatory behaviors}

Less than $10 \%$ of the respondents reported preoperative and postoperative self-induced vomiting, laxatives, and diuretics. Within the bariatric field, studies that focus on compensatory behaviors are scarce. ${ }^{6}$ Vomiting has not only been reported mainly in the first few months postoperatively in one-third to two-thirds of patients, but it has also been reported several years postoperatively. Vomiting was associated with malnutrition or with the risk of developing softcaloric syndrome, in which an excess of high-calorie soft or meltable foods or liquids is consumed. ${ }^{4}$ Compensatory behavior in our study was hardly reported. Comparison of these results with results in the literature is limited, and underreporting cannot be ruled out.

\section{Excessive exercise to reduce weight (compensatory behavior)}

A daily minimum of 60 min of moderate- to vigorousintensity physical activity is required for long-term weight loss. ${ }^{5}$ The duration of physical activity in subjects with suboptimal weight loss and weight regain was significantly lower than in subjects with weight loss. ${ }^{13}$ Physical activity has been associated not only with enhanced weight loss outcomes but also weight regain. ${ }^{5}$ This implies a U-shaped association: at one end of the continuum, activity helps in losing weight, but at a certain point, excessive exercise is no longer an advantage. In our survey, participants were asked if they engaged in exercise three times or more per week solely to reduce weight, implying unhealthy behavior. After surgery, the frequency increased from $16 \%$ to $24 \%$, but weight loss varied extensively and was independent of the amount of exercise.

In literature, exercise levels have been found to be an area of noncompliance. ${ }^{16}$ One study found that after surgery, the most frequently reported services completed were support groups and dietary consultation. ${ }^{17}$ Half of the responders did 
not meet an exercise professional. Exercise services received the lowest satisfaction rating. ${ }^{17}$ Two studies reported a significant increase in physical activity within the first 2 years after surgery, ${ }^{12,14}$ but less compliance with physical activity was found in the second year and $25 \%$ of the participants did not engage in any physical activity. ${ }^{12}$ The impact of physical activity on postoperative weight and weight maintenance needs more research. ${ }^{6}$ A review concluded that the hypothesis that exercise could play a crucial role in weight loss maintenance still needs to be tested more, especially in the long run. ${ }^{18}$

\section{Network analysis: guideline compliance and weight}

A previous study showed that compliance with postoperative guidelines was associated with more weight loss, ${ }^{2}$ but even in the high compliance group, weight loss decreased over time. ${ }^{2}$ In our study, only postoperative restrained eating was significantly associated with reduced weight loss, but other factors could still be relevant from a clinical point of view. To clarify this, a network was generated (Fig. 1) to explore possible behavioral associations that might in the future add to the theory. Vitamin use had a central position in the behavior network and has, for example, a positive correlation (gray line) with meals spread during the day and amount of food. Vitamin use has a negative correlation (white line) with vomiting and restrained eating. The correlations might be useful for future research exploring these issues in more detail.

Compliance with postsurgical guidelines remains necessary because they have the potential to obstruct weight loss. Patients should be informed that noncompliance is a risk for suboptimal outcomes. Health education remains important because compliance with health-related behavior diminished over time. ${ }^{12}$ A previous study showed that increasing awareness regarding eating behavior helped improve the success of bariatric surgery. ${ }^{19}$

\section{Satisfaction regarding the weight loss trajectory after bariatric surgery}

The second aim was to assess the associations between compliance with dietary guidelines and satisfaction regarding the trajectory after bariatric surgery. Compliance with postsurgical dietary guidelines was found to be important to achieve a satisfactory level of well-being and quality of life. ${ }^{8}$ In our study, subjects with the most unhealthy behavior more often regretted having the bariatric procedure. One hypothesis is that postoperative unhealthy behavior reflected difficulty adjusting to a new lifestyle. Subsyndromal eating pathology could be another factor, but this is poorly understood. Although candidates with eating disorders were excluded, underlying dysfunctional eating dynamics cannot be ruled out. The above results need replication, but it seems wise to discuss healthy and unhealthy behaviors with patients to maximize the probability of success.

Although the precise meaning is not clear yet, it might be helpful that professionals use information on the patient's alcohol use, restrained eating, and excessive sports next to nonvitamin use to support them in healthy behavior, even after 5 years.

\section{Methodological issues}

The present study added information to the limited number of long-term studies that have been reported and the even smaller pool of results from the patient perspective. In addition, the prospective data collection avoids recall bias. Nevertheless, some limitations are apparent.

First, the data collection in 2005 could be marked as dated, but the conviction of the authors was that the presented results still provided meaningful insight into postoperative behavior in the long term. Postsurgical guidelines still match the advice given today. Studies concerning this issue are still scarce. Maladaptive eating was found regardless of the type of surgery. ${ }^{20}$ There are no indications that modern bariatric techniques specifically obstruct or facilitate adaptation to a postoperative lifestyle.

Second, the sample size was relatively small. Thus, the results are explorative and need to be replicated in future studies. In addition, because the power was low, not all reported associations reached statistical significance. The small sample size was the main reason to not exclude the six participants who had postponed their surgery and therefore these patients did not have a mean postoperative follow-up of at least 2 years at the first follow-up. Including all 490 names from the original sample would have led to sufficient power, but was not feasible with the available resources. To increase the response rate, participants received a questionnaire rather than an invitation to visit the hospital.

Third, patients may overreport positive medical outcomes or underreport negative outcomes. These phenomena also cannot be ruled out in validated instruments. The current results match those of other long-term studies that did include objective weight assessment. Long-term results based on objective measurements are crucial, but the focus of the present study was on patient-centered outcomes. To increase the response rate, questionnaires were used rather than assessment at the hospital.

Finally, patients lost to follow-up tended to lose less weight, revealing the importance of complete follow-up. Differential attrition may create a particular challenge in assessing bariatric surgical outcomes as it is likely that the bariatric surgery patients who are not doing well are the most hesitant to engage in follow-up procedures. Because of the relatively low number of participants and the exploratory nature of the study, sensitivity analyses using the intention-to-treat principle (e.g., last observation carried forward) were not performed. Future larger studies should perform sensitivity analyses to examine any potential bias due to differential attrition.

\section{Informed Consent}

Written informed consent was obtained from all individual participants included in the study.

\section{Author Disclosure Statement}

The authors declare that they have no conflicts of interest.

\section{Funding Information}

The authors received no financial support for the research presented in the article.

\section{References}

1. Bastos EC, Barbosa EM, Soriano GM, dos Santos EA, Vasconcelos SM. Determinants of weight regain after bariatric surgery. Arq Bras Cir Dig 2013;26(Suppl. 1):26-32. 
2. Sarwer DB, Wadden TA, Moore RH, Baker AW, Gibbons LM, Raper SE, et al. Preoperative eating behavior, postoperative dietary adherence, and weight loss after gastric bypass surgery. Surg Obes Relat Dis 2008;4:640-646.

3. Wimmelmann CL, Dela F, Mortensen EL. Psychological predictors of weight loss after bariatric surgery: a review of the recent research. Obes Res Clin Pract 2014;8:e299-e313.

4. Sarwer DB, Dilks RJ, West-Smith L. Dietary intake and eating behavior after bariatric surgery: threats to weight loss maintenance and strategies for success. Surg Obes Relat Dis 2011;7:644-651.

5. McGrice M, Don Paul K. Interventions to improve longterm weight loss in patients following bariatric surgery: challenges and solutions. Diabetes Metab Syndr Obes 2015;8:263-274.

6. Elfhag K, Rossner S. Who succeeds in maintaining weight loss? A conceptual review of factors associated with weight loss maintenance and weight regain. Obes Rev 2005;6:67-85.

7. Brandao I, Ramalho S, Pinto-Bastos A, Arrojado F, Faria G, Calhau C, et al. Metabolic profile and psychological variables after bariatric surgery: association with weight outcomes. Eat Weight Disord 2015;20:513-518.

8. Prazeres de Assis P, Alves da Silva S, Sousa Vieira de Melo CY, de Arruda Moreira M. Eating habits, nutritional status and quality of life of patients in late postoperative gastric bypass Roux-Y. Nutr Hosp 2013;28:637-642.

9. Hindle A, de la Piedad Garcia X, Brennan L. Early postoperative psychosocial and weight predictors of later outcome in bariatric surgery: a systematic literature review. Obes Rev 2017;18:317-334.

10. Richardson WS, Plaisance AM, Periou L, Buquoi J, Tillery D. Long-term management of patients after weight loss surgery. Ochsner J 2009;9:154-159.

11. Epskamp S, Cramer AOJ, Waldorp LJ, Schmittmann VD, Borsboom D. qgraph: network visualizations of relationships in psychometric data. J Stat Softw 2012;48:1-18.

12. Kafri N, Valfer R, Nativ O, Shiloni E, Hazzan D. Health behavior, food tolerance, and satisfaction after laparoscopic sleeve gastrectomy. Surg Obes Relat Dis 2011;7:82-88.
13. Amundsen T, Strommen M, Martins C. Suboptimal weight loss and weight regain after gastric bypass surgery-postoperative status of energy intake, eating behavior, physical activity, and psychometrics. Obes Surg 2017;27:1316-1323.

14. Silver HJ, Torquati A, Jensen GL, Richards WO. Weight, dietary and physical activity behaviors two years after gastric bypass. Obes Surg 2006;16:859-864.

15. Conason A, Teixeira J, Hsu CH, Puma L, Knafo D, Geliebter A. Substance use following bariatric weight loss surgery. JAMA Surg 2013;148:145-150.

16. King WC, Bond DS. The importance of preoperative and postoperative physical activity counseling in bariatric surgery. Exerc Sport Sci Rev 2013;41:26-35.

17. Peacock JC, Zizzi SJ. Survey of bariatric surgical patients' experiences with behavioral and psychological services. Surg Obes Relat Dis 2012;8:777-783.

18. Coen PM, Carnero EA, Goodpaster BH. Exercise and bariatric surgery: an effective therapeutic strategy. Exerc Sport Sci Rev 2018;46:262-270.

19. Klem ML, Wing RR, McGuire MT, Seagle HM, Hill JO. A descriptive study of individuals successful at long-term maintenance of substantial weight loss. Am J Clin Nutr 1997;66:239-246.

20. Pizato N, Botelho PB, Goncalves VSS, Dutra ES, de Carvalho KMB. Effect of grazing behavior on weight regain post-bariatric surgery: a systematic review. Nutrients 2017; 9:E1322.

Address correspondence to: Gerdy Konings, BA

Department of Medical Psychology Maastricht University Medical Centre (MUMC)

PO Box 5800

Maastricht 6202 AZ The Netherlands

E-mail: g.konings@mumc.nl 